\title{
CLINICAL FINDINGS AND PROGNOSIS OF HOSPITALIZED ELDERLY COVID-19 PATIENTS
}

Turkish Journal of Geriatrics

DOI: 10.31086/tigeri.2021.194

2021; 24(1): $1-12$

\section{- Öner BOZAN ${ }^{1}$}

- Şeref Emre ATiş²

- Bora ÇEKMEN ${ }^{3}$

- Mehmet Taylan KOÇER ${ }^{1}$

- Yavuzselim KOCA ${ }^{1}$

- Edip Burak KARAASLAN ${ }^{1}$

- Mücahit ŞENTÜRK ${ }^{1}$

- Funda ŞiMŞEK ${ }^{4}$

- Asım KALKAN ${ }^{1}$

CORRESPONDANCE

\section{${ }^{1}$ Öner BOZAN}

Prof. Dr. Cemil Taşçıŏlu City Hospital, Department of Emergency Medicine, Istanbul, Turkey

\section{Phone: +902123145555 \\ e-mail: onerbozan@gmail.com}

Received: Nov 28, 2020

Accepted: Feb 22, 2020

1 Prof. Dr. Cemil Taşçıŏlu City Hospital, Department of Emergency Medicine, İstanbul, Turkey

2 Mersin City Hospital, Department of Emergency Medicine, Mersin, Turkey

${ }^{3}$ Karabuk University Faculty of Medicine, Department of Emergency Medicine, Karabük, Turkey

4 Prof. Dr. Cemil Taşçıŏlu City Hospital, Department of Infectious Diseases and Clinical Microbiology, İstanbul, Turkey

\section{Abstract}

Background: SARS-CoV-2 has caused an outbreak all over the World. Age is the most important factor for mortality. However, it is not known exactly why SARS-CoV-2 infections are more severe and fatal in the elderly population. We examined the clinical course and the causes of increasing mortality in all hospitalized patients diagnosed with COVID-19 over 65 years of age.

Methods: Hospitalized elderly patients diagnosed with COVID-19 were examined in this retrospective observational study. The blood results, length of stay, comorbid diseases, admission symptoms, clinical results and demographic data of the patients were recorded. It was examined whether there was a significant difference between surviving and non-surviving patients in terms of comorbid diseases and symptoms. The effects of these parameters on the 30-day mortality alone were investigated.

Results: A total of 263 patients (125 males) were included in the study. Cough (53.2\%) followed by dyspnea (35.7\%) were the two most common symptoms. There was no statistically significant difference age or sex distribution between survivor and nonsurvivor patients. Patients with dyspnea had a significantly lower survival rate compared to patients who did not have dyspnea at presentation and patients who have chronic obstructive pulmonary disease and cerebrovascular disease were associated with a significantly increased risk of mortality Conclusions:

It has been shown that there is a significant increase in the risk of mortality in COVID-19 patients with chronic obstructive pulmonary disease and cerebrovascular diseases. Additionally, Dyspnea, as an admission symptom, were found to have an effect on mortality and clinical outcomes in our study.

Key words: Coronavirus Infections; Frail Elderly; Hospital Mortality; Dyspnea; Pulmonary Disease, Chronic Obstructive 


\section{INTRODUCTION}

In December 2019, an outbreak of pneumonia and severe acute respiratory syndrome in Wuhan, China led to the identification of a novel coronavirus, SARS-CoV-2 (1). The disease, COVID-19, has been declared a global pandemic by the World Health Organization (WHO), and virus-related disease and death has spread rapidly around the world with serious consequences for public health (2).

The disease has a severe progression, and its mortality rate is higher in elderly patients $(3,4)$. Age alone is by far the most important risk factor for COVID-19-related mortality (5). However, it is not known exactly why SARS-CoV-2 infections are more severe and fatal in the elderly population. Many hypotheses have been proposed to explain high mortality in patients over 65 years of age $(5,6)$. There is a need for more studies describing the clinical course, response to treatment, and outcomes of elderly patients diagnosed with COVID-19.

COVID-19 patients of advanced age and with comorbidities have poor prognosis $(3,4)$. We aimed to determine which factors in addition to these two affect the clinical course and mortality in patients over 65 years of age. In this retrospective observational study, the relationship between admission symptoms and/or comorbid diseases and mortality was investigated in patients over 65 years of age who were admitted to hospital through the emergency department.

\section{MATERIALS AND METHODS}

Our institution is a tertiary training and research hospital appointed as a pandemic hospital by the Republic of Turkey, Ministry of Health. The ethics committee of the hospital study site approved the study (48670771-514.10-208). Hospitalized patients over 65 years of age who were diagnosed with COVID-19 by polymerase chain reaction (PCR) at the time of admission were included in the study, and their records were retrospectively examined.
Patients over 65 years of age who had negative results at the time of admission that turned positive in repeated tests during their stay were also included in the study.

Those with incomplete data in their files, those not hospitalized after admission to the emergency department, and those with repeated negative PCR test results were excluded from the study. Complete blood count results, length of stay, comorbid diseases, admission symptoms, clinical results and demographic data of the patients diagnosed with COVID-19, obtained from the Hospital Information System, were recorded in patient information forms for analysis by emergency physicians.

Admission to the ward, admission to the intensive care unit, and 30-day mortality data were recorded by analyzing how hospital admissions ended. Both the Death Reporting System (OBS, http:// www.obs.gov.tr) and patient files were checked for the death status and date when calculating the 30-day mortality. Patients were divided into two groups, mortality and surviving, according to their clinical outcomes. The effects of comorbid diseases and admission symptoms on mortality within a 30day period were investigated.

\section{Statistical Analysis}

To summarize the data derived from the study, descriptive statistics were presented as mean \pm standard deviation and median (interquartile range). Categorical variables were expressed as number and percentage. The Kolmogorov-Smirnov and Shapiro Wilks tests were used to check the normality of the numerical variables. Besides, visual methods such as skewness and kurtosis coefficients, histogram, Q-Q plot, and boxplot were also used in the evaluation of the distribution of the variables.

For the comparison of two independent groups, Independent Samples $t$ test and Mann-Whitney $U$ test were used for continuous variables in case of normal and non-normal distribution, respectively. 
In comparisons related to patient admission, the Kruskall Wallis test was used when the variables were not normally distributed.

Pairwise comparisons in nonparametric tests were performed with the Dwass-Steel-CritchlowFligner test.

In the comparison of categorical variables, Pearson chi-square or Fisher's exact test was used (when the expected values were below 5). In RxC tables where the expected values were below 5 , the Fisher Freeman Halton test was used.

Kaplan-Meier survival analysis and a Log Rank test were performed to determine the relationship between the presence of dyspnea and admission setting with survival rates.

The factors that have an influence on patient outcomes were evaluated with both univariate and multivariate Cox regression models. In selecting the parameters included in the multivariate model, the status of significance of the variables in the univariate models as well as the clinical relevance of the variables were taken into consideration. On the other hand, when independent variables showed strong correlation with each other, one of them was left out of the multivariate regression model.

Jamovi project (Version 1.2.22) and JASP (Version 0.13 ) were used to perform the statistical analyses. A p-value of $<0.05$ was considered statistically significant.

\section{RESULTS}

Demographics, baseline characteristics, and admission laboratory values

A total of 263 patients (125 males) were included in the study. The mean age of the patients was $75.4 \pm 8.0$ years. Eleven different symptoms were recorded for all patients, the most common of which was cough (53.2\%). Dyspnea was the second most commonly encountered symptom (35.7\%). The least commonly detected symptom was dysgeusia and loss of smell, and was present in only one patient. We grouped the most commonly seen symptoms (fever, cough, dyspnea, and myalgia-arthralgia) in one category, "most common four." The median number of symptoms was 2.0 [IQR: 0.0- 6.0]. The percentage of patients who had at least one of the "most common four" was $86.7 \%(n=228)$. The most frequent comorbid disease among the patients was hypertension (54\%), followed by diabetes mellitus (39.9\%). Overall, $76.8 \%$ of the study population had at least one comorbid disease. The median number of comorbid diseases was 1.0 [IQR: 0.0- 5.0] in the whole group.

The majority of the study patients were admitted to a hospital ward (77.2\%). In the end, while 205 patients $(77.9 \%)$ were discharged from the hospital, 58 patients $(22.1 \%)$ died. Median lengths of hospital stay were 12.0 [IOR: 1.0- 60.0] days and 9.0 [IQR: 1.0- 33.0] days in the general hospital ward and ICU, respectively.

Age and sex distribution, admission symptoms, comorbid conditions and baseline laboratory values of the entire study group are shown in Table 1.

Patient and laboratory characteristics according to admission setting

There was no statistically significant difference in terms of age and sex distribution between the patients who were admitted to ICU, to the ward, or who were transferred to ICU from the ward. The only symptom that showed a significant difference among the groups was dyspnea. It was present in $89.5 \%$ of patients in ICU, whereas $30.5 \%$ of ward patients had dyspnea $(p<0.001)$. Among ICU patients, dyspnea was the most common symptom. The second most frequent symptom was cough ( $31.6 \%$, see Table 2). Cerebrovascular disease was significantly more prevalent in ICU patients compared with ward patients $(p=0.024)$. The number of comorbid conditions was significantly higher in the ICU patients and the patients who transferred to the ICU compared with the patients who were admitted to the ward ( $p=0.016$, see Table 2). 
Table-1. Age and sex distribution, admission symptoms, comorbid conditions and baseline laboratory values of the entire study group.

\begin{tabular}{|c|c|c|}
\hline & Mean \pm SD / n (\%) & Median [Min- Max] \\
\hline Age (years) & $75.4 \pm 8.0$ & 74.0 [65.0- 98.0] \\
\hline \multicolumn{3}{|l|}{ Sex } \\
\hline Male & $125(47.5)$ & \\
\hline Female & $138(52.5)$ & \\
\hline \multicolumn{3}{|l|}{ Admission symptoms } \\
\hline Fever & $77(29.3)$ & \\
\hline Cough & $140(53.2)$ & \\
\hline Dyspnea & $94(35.7)$ & \\
\hline Myalgia-arthralgia & $79(30.0)$ & \\
\hline Anorexia & $13(4.9)$ & \\
\hline Headache & $11(4.2)$ & \\
\hline Diarrheae & $9(3.4)$ & \\
\hline Nausea and vomiting & $19(7.2)$ & \\
\hline Abdominal pain & $4(1.5)$ & \\
\hline Dysgeusia and loss of smell & $1(0.4)$ & \\
\hline Sore throat & $6(2.3)$ & \\
\hline \multicolumn{3}{|l|}{ Comorbid conditions } \\
\hline Hypertension & $142(54.0)$ & \\
\hline Diabetes mellitus & 105 (39.9) & \\
\hline Maligancy & $19(7.2)$ & \\
\hline Asthma & $14(5.3)$ & \\
\hline Coronary artery disease & $56(21.3)$ & \\
\hline Cerebrovascular diseases & $20(7.6)$ & \\
\hline Chronic kidney disease & $33(12.5)$ & \\
\hline Chronic liver disease & $1(0.4)$ & \\
\hline Chronic obstructive lung disease & $19(7.2)$ & \\
\hline Number of patients with at least one comorbid condition & $202(76.8)$ & \\
\hline Number of symptoms & $1.7 \pm 1.0$ & $2.0[0.0-6.0]$ \\
\hline Number of comorbid conditions & $1.6 \pm 1.2$ & $1.0[0.0-5.0]$ \\
\hline \multicolumn{3}{|l|}{ Admission setting } \\
\hline Ward & $203(77.2)$ & \\
\hline Transfer from the ward to ICU & $41(15.6)$ & \\
\hline Intensive care unit (ICU) & $19(7.2)$ & \\
\hline \multicolumn{3}{|l|}{ Survival status } \\
\hline Survival & $205(77.9)$ & \\
\hline Death & $58(22.1)$ & \\
\hline Length of hospital stay (days) & $12.6 \pm 7.7$ & $12.0[1.0-60.0]$ \\
\hline
\end{tabular}




\begin{tabular}{|c|c|c|}
\hline Length of ICU stay (days) & $10.5 \pm 8.1$ & $9.0[1.0-33.0]$ \\
\hline \multicolumn{3}{|l|}{ Laboratory Parameters } \\
\hline WBC $\left(10^{3} / \mu L\right)$ & $7.7 \pm 4.4$ & $6.7[1.2-45.5]$ \\
\hline Hemoglobin $(g / L)$ & $120.6 \pm 18.9$ & $120.0[48.0-182.0]$ \\
\hline Neutrophil count $\left(10^{3} / \mu \mathrm{L}\right)$ & $9.5 \pm 58.5$ & $5.0[0.8-952.0]$ \\
\hline Lymphocyte count $\left(10^{3} / \mu \mathrm{L}\right)$ & $1.4 \pm 2.1$ & $1.2[0.2-31.9]$ \\
\hline Platelet count $\left(10^{3} / \mu \mathrm{L}\right)$ & $202.7 \pm 87.3$ & $195.0[28.0-681.0]$ \\
\hline Creatinine $(\mathrm{mg} / \mathrm{dL})$ & $1.5 \pm 1.8$ & $1.0[0.3-18.7]$ \\
\hline Lactate dehydrogenase (LDH) (U/L) & $307.7 \pm 210.4$ & $277.0[0.0-2135.0]$ \\
\hline D-dimer (ug/L) & $2898.9 \pm 8341.5$ & $938.0[0.0-100000.0]$ \\
\hline Procalcitonin $(\mu \mathrm{g} / \mathrm{L})$ & $0.5 \pm 2.0$ & $0.0[0.0-23.0]$ \\
\hline Lactate $(\mathrm{mmol} / \mathrm{L})$ & $0.8 \pm 1.2$ & $0.0[0.0-6.8]$ \\
\hline C-reactive protein $(\mathrm{mg} / \mathrm{L})$ & $85.0 \pm 80.1$ & $66.9[0.0-513.8]$ \\
\hline Glomerular filtration rate $\left(\mathrm{mL} / \mathrm{dk} / 1.73 \mathrm{~m}^{2}\right)$ & $63.0 \pm 33.0$ & $62.0[2.0-226.7]$ \\
\hline
\end{tabular}

Descriptive statistics were expressed as mean \pm standard deviation and median (IQR) for metric variables. Categorical variables were presented as number (\%). P-values written in bold are statistically significant $(p<0,05)$. IQR: Interquartile range

Mortality rate was significantly higher in ICU patients $(94.7 \%)$ and patients who transferred to the ICU (85.4\%) compared to ward patients (2.5\%). The median length of hospital stay was significantly longer in patients who transferred to the ICU compared with the other two groups $(p<0.001)$.

Most of the laboratory values examined were comparable between ICU patients and patients transferred from ward to ICU. An exception was serum lactate level, which was significantly higher in ICU patients (Table 2). On the other hand, median lymphocyte counts, lactate dehydrogenase, and procalcitonin were not statistically different between ward patients and ICU patients. White blood cell and neutrophil counts, C-reactive protein, and d-dimer were significantly higher in ICU patients compared to ward patients. Ward patients had a significantly higher glomerular filtration rate (GFR) compared to ICU patients.

Patient and laboratory characteristics according to survival status

There was no statistically significant difference in mean age or sex distribution between survivor and nonsurvivor patients. Multivariate Cox regression indicated that a dyspnea is associated with increased 30-day mortality, and it is an independent predictor of long-term survival ( $p=0.001)$. The number of symptoms were comparable between the two groups. On the other hand, the median number of comorbid conditions was significantly higher among death patients compared to surviving patients $(p=0.028)$. However, there was no difference in the frequency of any individual comorbid disease between the groups. The length of the hospital and ICU stay in the two groups was not statistically significant.

The median values of white blood cell count, neutrophil count, and C-reactive protein were significantly higher in the mortality group compared to the discharged group $(p<0.001)$, whereas the lymphocyte count and platelet count were significantly lower. Moreover, the median values of serum lactate dehydrogenase, lactate, and d-dimer were also significantly higher in the death patients compared to discharged patients. Table 3 summarizes the laboratory parameters and clinical characteristics in survivor and nonsurvivor patients. 
Table-2. Comparison of mean age and sex distribution, admission symptoms, comorbid conditions and baseline laboratory values according to admission setting

\begin{tabular}{|c|c|c|c|c|}
\hline & \multicolumn{3}{|c|}{ Admission setting } & \multirow[b]{2}{*}{ P-value } \\
\hline & Ward $(n=203)$ & $\begin{array}{l}\text { From Ward to ICU } \\
\qquad(n=41)\end{array}$ & $\underset{(n=19)}{\text { ICU }}$ & \\
\hline Age (median [IQR]) & $75.0[69.0-81.0]$ & $73.0[67.0-78.0]$ & $78.0[71.0-80.5]$ & $0.182^{* \star}$ \\
\hline \multicolumn{5}{|l|}{ Sex $(\%)$} \\
\hline Male & $94(46.3)$ & $24(58.5)$ & $7(36.8)$ & $0.225^{*}$ \\
\hline Female & $109(53.7)$ & $17(41.5)$ & $12(63.2)$ & \\
\hline Fever & $59(29.1)$ & $15(36.6)$ & $3(15.8)$ & $0.255^{*}$ \\
\hline Cough & $113(55.7)$ & $21(51.2)$ & $6(31.6)$ & $0.127^{*}$ \\
\hline Dyspnea & $62(30.5)^{a}$ & $15(36.6)^{a}$ & $17(89.5)^{b}$ & $<0.001^{\star}$ \\
\hline Myalgia-arthralgia & $62(30.5)$ & $15(36.6)$ & $2(10.5)$ & $0.116^{*}$ \\
\hline Anorexia & $9(4.4)$ & $4(9.8)$ & $0(0.0)$ & $0.272^{*}$ \\
\hline Headache & $11(5.4)$ & $0(0.0)$ & $0(0.0)$ & $0.304^{*}$ \\
\hline Diarrheae & $5(2.5)$ & $4(9.8)$ & $0(0.0)$ & $0.058^{*}$ \\
\hline Nausea and vomiting & $14(6.9)$ & $5(12.2)$ & $0(0.0)$ & $0.25^{\star}$ \\
\hline Abdominal pain & $3(1.5)$ & $0(0.0)$ & $1(5.3)$ & $0.349^{*}$ \\
\hline Dysgeusia and loss of smell & $1(0.5)$ & $0(0.0)$ & $0(0.0)$ & $0.999^{*}$ \\
\hline Sore throat & $4(2.0)$ & $2(4.9)$ & $0(0.0)$ & $0.538^{*}$ \\
\hline Number of symptoms (median [IQR]) & $2.0[1.0-2.0]$ & $2.0[1.0-3.0]$ & $1.0[1.0-2.0]$ & $0.202^{\star *}$ \\
\hline Number of major 4 symptoms (median [IQR]) & $2.0[1.0-2.0]$ & $2.0[1.0-2.0]$ & $1.0[1.0-2.0]$ & $0.544^{\star *}$ \\
\hline Hypertension & $107(52.7)$ & $26(63.4)$ & $9(47.4)$ & $0.380^{*}$ \\
\hline Diabetes mellitus & 75 (36.9) & $20(48.8)$ & $10(52.6)$ & $0.185^{*}$ \\
\hline Maligancy & $14(6.9)$ & $4(9.8)$ & $1(5.3)$ & $0.829^{*}$ \\
\hline Asthma & $12(5.9)$ & $1(2.4)$ & $1(5.3)$ & $0.788^{*}$ \\
\hline Coronary artery disease & $38(18.7)$ & $11(26.8)$ & $7(36.8)$ & $0.121^{*}$ \\
\hline Cerebrovascular disease & $11(5.4)^{a}$ & $6(14.6)^{b}$ & $3(15.8)^{a, b}$ & $0.024^{\star}$ \\
\hline Chronic kidney disease & $22(10.8)$ & $9(22.0)$ & $2(10.5)$ & $0.135^{*}$ \\
\hline Chronic liver disease & $1(0.5)$ & $0(0.0)$ & $0(0.0)$ & $0.999^{*}$ \\
\hline Chronic obstructive lung disease & $12(5.9)$ & $3(7.3)$ & $4(21.1)$ & $0.063^{*}$ \\
\hline Number of comorbid conditions & $1.0[1.0-2.0]^{a}$ & $2.0[1.0-3.0]^{b}$ & $2.0[1.0-3.0]^{a, b}$ & $0.016^{* *}$ \\
\hline $\begin{array}{l}\text { Number of patients with at least one } \\
\text { comorbid condition }\end{array}$ & $153(75.4)$ & $34(82.9)$ & $15(78.9)$ & $0.607^{\star}$ \\
\hline \multicolumn{5}{|l|}{ Survival status } \\
\hline Discharge & $198(97.5)^{a}$ & $6(14.6)^{b}$ & $1(5.3)^{b}$ & $<0.001^{*}$ \\
\hline Exitus & $5(2.5)^{a}$ & $35(85.4)^{b}$ & $18(94.7)^{b}$ & \\
\hline Length of hospital stay (median [IQR]) & $11.0[7.0-14.0]$ & $16.0[11.0-23.0]$ & $12.0[5.5-14.5]$ & $<0.001^{\star *}$ \\
\hline Length of ICU stay (median [IQR]) & NA [NA-NA] & $9.0[4.0-14.0]$ & $9.0[5.5-14.0]$ & $0.519^{\star \star}$ \\
\hline WBC $\left(10^{3} / \mu \mathrm{L}\right)$ & $6.5[5.1-8.3]^{a}$ & $7.3[5.9-10.2]^{a, b}$ & $9.2[7.2-13.6]^{b}$ & $<0.001^{\star *}$ \\
\hline Hemoglobin $(\mathrm{g} / \mathrm{L})$ & $120.0[108.0-133.0]$ & $121.0[98.0-132.0]$ & 118.0 [104.5-133.0] & $0.769^{\star \star}$ \\
\hline
\end{tabular}




\begin{tabular}{|c|c|c|c|c|}
\hline Neutrophil count $\left(10^{3} / \mu \mathrm{L}\right)$ & $4.7[3.4-6.2]^{\text {a }}$ & $5.8[4.3-8.9]^{b}$ & $7.3[5.4-11.7]^{b}$ & $<0.001^{\star \star}$ \\
\hline Lymphocyte count $\left(10^{3} / \mu \mathrm{L}\right)$ & $1.2[0.9-1.7]^{a}$ & $0.9[0.7-1.2]^{b}$ & $1.1[0.7-1.7]^{a, b}$ & $0.002^{\star \star}$ \\
\hline Platelet count $\left(10^{3} / \mu \mathrm{L}\right)$ & $198.0[146.0-242.5]$ & $182.0[130.0-224.0]$ & 220.0 [155.0-261.0] & $0.448^{\star *}$ \\
\hline Creatinine $(\mathrm{mg} / \mathrm{dL})$ & $0.9[0.7-1.2]^{a}$ & $1.2[1.0-2.4]^{b}$ & $1.4[1.0-1.8]^{b}$ & $<0.001^{\star *}$ \\
\hline Lactate dehydrogenase (LDH) (U/L) & $256.0[193.5-337.5]^{a}$ & $353.0[268.0-529.0]^{b}$ & $430.0[362.0-542.0]^{a, b}$ & $<0.001^{\star \star}$ \\
\hline D-dimer (ug/L) & $865.0[495.5-1670.0]^{a}$ & $1380.0[840.0-2040.0]^{b}$ & $2720.0[1300.0-3925.0]^{c}$ & $<0.001^{\star *}$ \\
\hline Procalcitonin $(\mu \mathrm{g} / \mathrm{L})$ & $0.0[0.0-0.2]^{a}$ & $0.4[0.2-0.8]^{b}$ & $0.3[0.1-0.8]^{a, b}$ & $<0.001^{\star \star}$ \\
\hline Lactate $(\mathrm{mmol} / \mathrm{L})$ & $0.0[0.0-1.0]^{a}$ & $1.4[0.0-1.8]^{b}$ & $2.5[1.4-3.9]^{\mathrm{c}}$ & $<0.001^{\star *}$ \\
\hline C-reactive protein (mg/L) & $52.7[15.3-104.3]^{a}$ & $113.7[67.1-170.9]^{\mathrm{b}}$ & $115.5[69.8-179.3]^{b}$ & $<0.001^{\star \star}$ \\
\hline Glomerular filtration rate $\left(\mathrm{mL} / \mathrm{dk} / 1.73 \mathrm{~m}^{2}\right)$ & $69.0[48.0-85.0]^{\mathrm{a}}$ & $55.0[22.0-69.0]^{b}$ & $39.0[29.5-57.0]^{b}$ & $<0.001^{\star \star}$ \\
\hline
\end{tabular}

*The Pearson Chi-squared or Fisher Freeman Halton test was used. Descriptive statistics were expressed as number (\%).

**The Kruskal Wallis test was used. Descriptive statistics were expressed as median [IQR]. P-values written in bold are statistically significant (p<0,05). IQR: Interquartile range

The comparisons which contain completely different letters are statistically different from each other.

\section{Survival analysis}

We performed survival analysis and constructed Kaplan Meier survival graphs based on different characteristics of the study population. Patients with dyspnea had a significantly lower survival rate compared to patients who did not have dyspnea at presentation (Figure 1).

ICU patients had the lowest survival rate. Compared with patients who were admitted to the ward, patients who were transferred from the ward to the ICU had a significantly shorter survival rate (Figure 2).

Cox regression analysis to determine the independent predictors of mortality

We performed Cox regression analysis to determine the independent predictors of mortality. We included significant variables from the univariate analysis in the multivariate analysis. However, we did not include variables which showed a significant and strong correlation with one another, so as not to weaken the effect of each other in the multivariate model.

Our Cox regression model revealed that the presence of chronic obstructive pulmonary disease (HR: 2.29 [IOR: 1.03-5.10], $p=0.043$ ) and cerebrovas- cular disease (HR: 2.36 [IQR: 1.18-4.73], $p=0.016)$ were associated with a significantly increased risk of mortality. An increased white blood cell count and a GFR lower than $60 \mathrm{~mL} / \mathrm{min}$ were also independent determinants of mortality. Although significant in the univariate analysis, the presence of dyspnea was not a significant predictor of the mortality in the multivariate model. Table-4 depicts the results of the univariate and multivariate Cox regression models.

\section{DISCUSSION}

The most common symptoms in our study were cough (53.7\%) and dyspnea (35.7\%). However, other studies reported fever as the primary symptom, and cough was reported as common $(7,8)$. We found that although the incidence of symptoms such as cough, fatigue, fever, loss of appetite, muscle pain, and diarrhea did not vary significantly between death and surviving patients, dyspnea, chest tightness, and consciousness disorders were more frequently observed in death patients. These symptoms indicate that the majority of death patients were in critical or severe condition at the time of admission. Indeed, the onset of certain symptoms can guide doctors to identify patients at risk of poor outcomes (9). How- 
Figure-1. Kaplan-Meier survival curves showing the comparison of the survival rates between the patients with and without dyspne within 30 days.

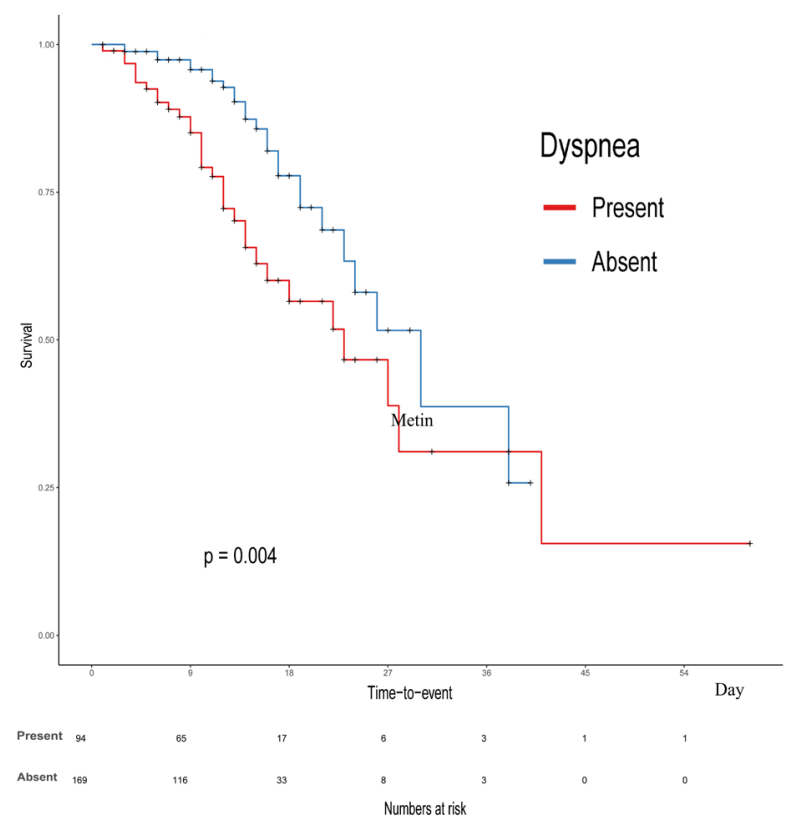

Figure-2. Kaplan-Meier survival curves showing the comparison of the survival rates between the patients who were admitted to the ICU, to the ward and transferred from ward to ICU.

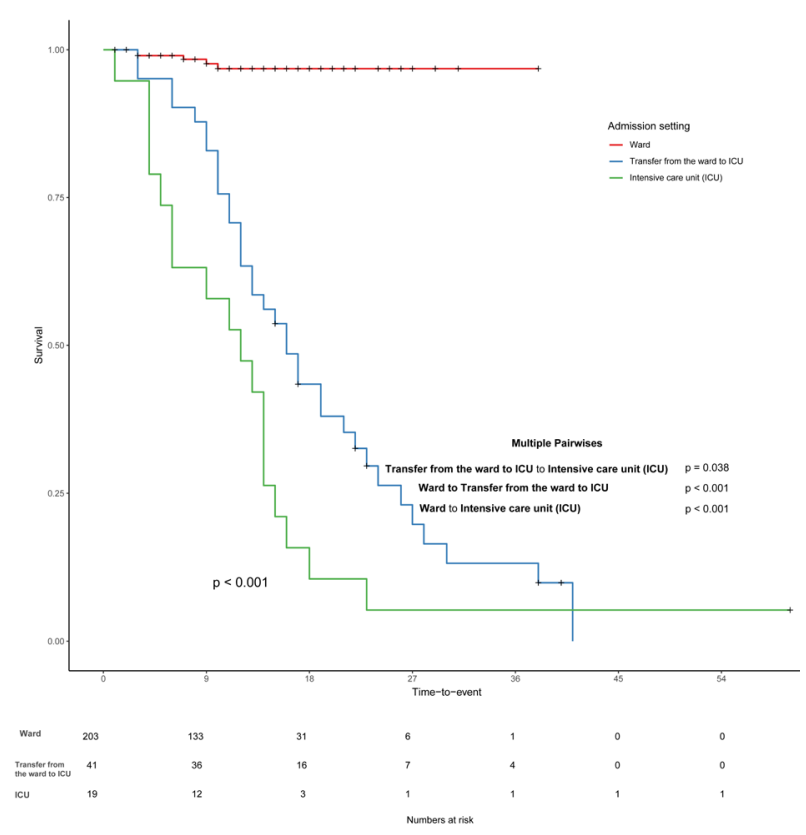

Table-3. Comparison of mean age and sex distribution, admission symptoms, comorbid conditions and baseline laboratory values between the patients who were survivor and nonsurvivor

\begin{tabular}{|c|c|c|c|}
\hline & \multicolumn{2}{|c|}{ Survival status } & \multirow[b]{2}{*}{ P-value } \\
\hline & Survivor $(n=205)$ & Nonsurvivor $(n=58)$ & \\
\hline Age & $75.4 \pm 8.1$ & $75.4 \pm 7.6$ & $0.963^{*}$ \\
\hline \multicolumn{4}{|l|}{ Sex (\%) } \\
\hline Male & $95(46.3)$ & $30(51.7)$ & $0.565^{\star \star}$ \\
\hline Female & $110(53.7)$ & $28(48.3)$ & \\
\hline Fever & $61(29.8)$ & $16(27.6)$ & $0.875^{* *}$ \\
\hline Cough & $115(56.1)$ & $25(43.1)$ & $0.109^{\star \star}$ \\
\hline Dyspnea & $62(30.2)$ & $32(55.2)$ & $0.001^{* \star}$ \\
\hline Myalgia-arthralgia & $64(31.2)$ & $15(25.9)$ & $0.533^{* *}$ \\
\hline Anorexia & $11(5.4)$ & $2(3.4)$ & $0.739^{* *}$ \\
\hline Headache & $11(5.4)$ & $0(0.0)$ & $0.129^{* *}$ \\
\hline Diarrheae & $5(2.4)$ & $4(6.9)$ & $0.111^{\star \star}$ \\
\hline Nausea and vomiting & $14(6.8)$ & $5(8.6)$ & $0.578^{* *}$ \\
\hline Abdominal pain & $3(1.5)$ & $1(1.7)$ & $0.999^{\star \star}$ \\
\hline Dysgeusia and loss of smell & $1(0.5)$ & $0(0.0)$ & $0.999^{* *}$ \\
\hline
\end{tabular}




\begin{tabular}{|c|c|c|c|}
\hline Sore throat & $5(2.4)$ & $1(1.7)$ & $0.999^{* *}$ \\
\hline Number of symptoms (median [IQR]) & $2.0[1.0-2.0]$ & $1.5[1.0-2.0]$ & $0.815^{\star \star \star}$ \\
\hline Number of major 4 symptoms (median [IQR]) & $2.0[1.0-2.0]$ & $1.0[1.0-2.0]$ & $0.911^{\star \star \star}$ \\
\hline Hypertension & $110(53.7)$ & $32(55.2)$ & $0.956^{* *}$ \\
\hline Diabetes mellitus & $79(38.5)$ & $26(44.8)$ & $0.477^{\star *}$ \\
\hline Maligancy & $14(6.8)$ & $5(8.6)$ & $0.578^{\star *}$ \\
\hline Asthma & $12(5.9)$ & $2(3.4)$ & $0.741^{* *}$ \\
\hline Coronary artery disease & $40(19.5)$ & $16(27.6)$ & $0.252^{* *}$ \\
\hline Cerebrovascular disease & $10(4.9)$ & $10(17.2)$ & $0.004^{\star *}$ \\
\hline Chronic kidney disease & $23(11.2)$ & $10(17.2)$ & $0.318^{* *}$ \\
\hline Chronic liver disease & $1(0.5)$ & $0(0.0)$ & $0.999^{* *}$ \\
\hline Chronic obstructive lung disease & $12(5.9)$ & $7(12.1)$ & $0.146^{* *}$ \\
\hline Number of comorbid conditions & $1.0[1.0-2.0]$ & $2.0[1.0-3.0]$ & $0.028^{\star \star \star}$ \\
\hline Number of patients with at least one comorbid condition & $154(75.1)$ & $48(82.8)$ & $0.298^{* *}$ \\
\hline Length of hospital stay (median [IQR]) & $11.0[7.0-15.0]$ & $12.0[8.2-17.0]$ & $0.323^{\star * \star}$ \\
\hline Length of ICU stay (median [IQR]) & $13.0[4.0-27.0]$ & $9.0[5.0-14.0]$ & $0.526^{\star \star \star}$ \\
\hline WBC $\left(10^{3} / \mu \mathrm{L}\right)$ & $6.9 \pm 3.1$ & $10.5 \pm 6.8$ & $<0.001^{*}$ \\
\hline Hemoglobin $(\mathrm{g} / \mathrm{L})$ & $121.3 \pm 17.2$ & $117.9 \pm 24.2$ & $0.322^{*}$ \\
\hline Neutrophil count $\left(10^{3} / \mu \mathrm{L}\right)$ & $4.6[3.4-6.2]$ & $6.9[5.3-10.3]$ & $<0.001^{\star * \star}$ \\
\hline Lymphocyte count $\left(10^{3} / \mu \mathrm{L}\right)$ & $1.2[0.9-1.7]$ & $0.9[0.6-1.3]$ & $<0.001^{\star \star \star}$ \\
\hline Platelet count $\left(10^{3} / \mu \mathrm{L}\right)$ & $197.0[146.0-242.0]$ & $192.5[133.8-253.8]$ & $0.87^{\star \star \star}$ \\
\hline Creatinine $(\mathrm{mg} / \mathrm{dL})$ & $0.9[0.8-1.2]$ & $1.3[1.0-2.2]$ & $<0.001^{\star \star \star}$ \\
\hline Lactate dehydrogenase (LDH) (U/L) & $260.0[195.0-340.0]$ & $389.0[282.5-530.5]$ & $<0.001^{\star * \star}$ \\
\hline D-dimer (ug/L) & $874.0[517.0-1680.0]$ & $1480.0[902.8-2795.0]$ & $<0.001^{\star \star \star}$ \\
\hline Procalcitonin $(\mu \mathrm{g} / \mathrm{L})$ & $0.0[0.0-0.2]$ & $0.3[0.1-0.8]$ & $<0.001^{\star \star \star}$ \\
\hline Lactate $(\mathrm{mmol} / \mathrm{L})$ & $0.0[0.0-1.1]$ & $1.4[0.0-2.1]$ & $<0.001^{\star \star \star}$ \\
\hline C-reactive protein $(\mathrm{mg} / \mathrm{L})$ & $52.3[15.7-98.5]$ & $121.9[77.5-188.6]$ & $<0.001^{\star \star \star}$ \\
\hline Glomerular filtration rate $\left(\mathrm{mL} / \mathrm{dk} / 1.73 \mathrm{~m}^{2}\right)$ & $68.0[48.0-85.0]$ & $49.0[26.2-68.8]$ & $<0.001^{\star * \star}$ \\
\hline
\end{tabular}

*Independent samples t-test was used. Descriptive statistics were expressed as mean \pm standard deviation for metric variables.

${ }^{\star *}$ The Pearson Chi-squared or Fisher Exact test was used. Descriptive statistics were expressed as number (\%).

***The Mann-Whitney $U$ test was used. Descriptive statistics were expressed as median [IQR].

$P$-values written in bold are statistically significant $(p<0,05)$. IQR: Interquartile range

ever, dyspnea in particular is probably a symptom of respiratory dysfunction and may reflect the severity of lung lesions caused by infection or inflammation (10). In our study, dyspnea was one of the most common symptoms and was the only symptom that showed a significant difference between ICU and ward patients as well as death and surviving patients. Dyspnea was found to be significantly higher in severe/critical patients compared to the other patients in several studies. It was suggested that this might be due to severe damage to the alveoli in the severe/critical group $(11,12)$. However, similar to our study, gastrointestinal symptoms were rarely reported in other studies (13).

We found significant differences between survivor and nonsurvivor patients in terms of laboratory 
Table-4. Univariate and multivariate Cox regression showing independent determinants of mortality

\begin{tabular}{|c|c|c|c|c|}
\hline & Crude HR $(95 \% \mathrm{Cl})$ & Crude P-value & Adjusted HR (95\%Cl) & P-value \\
\hline Dyspnea: & $2.13[1.26-3.59]$ & 0.005 & & \\
\hline COPD: & $2.39[1.07-5.31]$ & 0.033 & $2.29[1.03-5.10]$ & 0.043 \\
\hline CVD: & $2.11[1.06-4.21]$ & 0.034 & $2.36[1.18-4.73]$ & 0.016 \\
\hline Hypertension: & $0.75[0.44-1.27]$ & 0.282 & & \\
\hline Diabetes mellitus: & $1.18[0.70-2.00]$ & 0.532 & & \\
\hline White blood cell count & $1.05[1.02-1.07]$ & $<0.001$ & $1.04[1.02-1.07]$ & 0.002 \\
\hline GFR: $<60$ vs. $\geq 60 \mathrm{~mL} /$ minute & $1.75[1.02-3.00]$ & 0.041 & $1.58[0.90-2.76]$ & 0.111 \\
\hline Serum Lactate & $1.49[1.27-1.74]$ & $<0.001$ & & \\
\hline C-Reactive protein & $1.01[1.01-1.01]$ & $<0.001$ & & \\
\hline
\end{tabular}

COPD: Chronic obstructive pulmonary disease, CVD: Cerebrovascular diseases, GFR: Glomerular filtration rate, HR: Hazard ratio

findings. Leukocytosis of the patients was strongly associated with mortality. Nonsurvivor patients developed a statistically significant lymphopenia compared to surviving patients, but there was no statistically significant difference between ward and ICU patients in terms of lymphocyte counts. As shown in similar studies on lymphopenia, this suggests that cellular immunodeficiency is associated with poor prognosis. The degree of lymphocytopenia can reveal the severity of virus invasion or the state of antiviral immunity, thereby predicting the prognosis $(9,10,14,15)$. As in similar studies, the absolute value of lymphocytes decreased in most patients in our study. A low lymphocyte value can be used as reference index in the diagnosis of COVID-19 (16).

The median values of neutrophil count and C-reactive protein were also significantly higher in death compared to surviving patients; however, the platelet count was significantly lower. Serum lactate dehydrogenase, lactate, and D-dimer values were also significantly higher in death patients. As mentioned, we determined that a GFR of less than $60 \mathrm{~mL} / \mathrm{min}$ was an independent mortality predictor. Consistent with previous studies, our data suggest that GFR (a marker for renal failure) is a risk factor for in-hospital mortality $(17,18)$.

In our study, $76.8 \%$ of patients had at least one comorbid disease. The most common comorbidity was hypertension (54\%), followed by diabetes mellitus (39.9\%). In another study conducted in parallel with ours, the most common comorbidities reported were hypertension, diabetes mellitus, cardiovascular diseases, and cerebrovascular diseases (10). The number of comorbid conditions was significantly higher in ICU patients, and in patients transferred from ward to ICU after hospitalization, compared to ward patients. On the other hand, the median number of comorbid conditions was significantly higher in nonsurvivor patients compared to surviving patients. Comorbidities, especially cardiovascular diseases and chronic lung diseases, have been reported to be important in predicting in-hospital mortality in critical patients $(19,20)$. Similar studies revealed that more patients had underlying diseases, especially hypertension, lung diseases and heart diseases in the mortality group. In addition, in parallel with our results, multiple comorbidities were detected in more patients in the mortality group $(9,12)$.

These studies showed that the prevalence of chronic obstructive pulmonary disease (COPD) was 
low in COVID-19 patients, but disease severity and risk of mortality were high in COPD patients. In other studies, the risk of severe COVID-19 was reported to be four times higher in patients previously diagnosed with COPD compared to those without COPD $(21,22)$. In our study, COPD was found to increase the risk of mortality by approximately 2.2 times. We also found that the risk of mortality was increased by 2.3 times in the patients with cerebrovascular diseases. A combined analysis of other studies published to date show that, similar to our study, cerebrovascular diseases have been associated with a 2.5-fold increased likelihood of severe disease in patients with COVID-19 $(23,24)$.

\section{Limitations}

First, we collected epidemiological data, and this carries a risk of recall bias in our study. Secondly, due to the retrospective nature of the study, all laboratory tests were not performed in all patients, including lactate dehydrogenase, D-dimer, procalcitonin, and lactate; therefore, the role of these parameters in predicting in-hospital mortality may be underestimated. Thirdly, with approximately 12

\section{REFERENCES}

1. Lai CC, Shih TP, Ko WC, Tang HJ, Hsueh PR. Severe acute respiratory syndrome coronavirus 2 (SARSCoV-2) and coronavirus disease-2019 (COVID-19): The epidemic and the challenges. Int J Antimicrob Agents. 2020;55(3):105924. (PMID: 32081636)

2. WHO Director-General's opening remarks at the media briefing on COVID-19 - 11 March 2020. [Internet]. Available from: https://www.who.int/dg/speeches/ detail/who-director-general-s-opening-remarks-atthe-media-briefing-on-covid-19---11-march-2020. Accessed 17 November 2020.

3. Wilson N, Kvalsvig A, Barnard LT, Baker MG. Case-Fatality Risk Estimates for COVID-19 Calculated by Using a Lag Time for Fatality. Emerg Infect Dis. 2020;26(6):1339-1441. (PMID: 32168463)

4. Verity R, Okell LC, Dorigatti I, et al. Estimates of the severity of coronavirus disease 2019: a model-based days of hospitalization before death, there was not enough information about the dynamic changes in laboratory variables of death patients. Further research is needed to gain a better understanding of the risk factors and consequences for COVID-19, which will help guide efforts to reduce mortality.

\section{Conclusion}

Dyspnea, as an admission symptom, as well as COPD and cerebrovascular diseases were found to have an effect on mortality and clinical outcomes in our study. Our results emphasize the importance of preventive measures in elderly patients with one of these two comorbidities and of providing close follow-up of these patients if they contract COVID-19. In addition, special attention should be paid to elderly patients presenting with dyspnea in terms of medical care.

\section{Disclosure Statements}

Authors state that there is no conflict of interest in this article.

analysis Lancet Infect Dis. 2020;20(6):669-677. (PMID: 32240634)

5. Santesmasses D, Castro JP, Zenin AA, et al. COVID-19 is an emergent disease of aging. medRxiv; 2020. (PMID: 33006233)

6. Mueller AL, McNamara MS, Sinclair DA. Why does COVID-19 disproportionately affect older people? Aging (Albany NY). 2020;12(10):9959-9981. (PMID: 32470948)

7. Yang $X, Y u Y, X u J$, et al. Clinical course and outcomes of critically ill patients with SARS-CoV-2 pneumonia in Wuhan, China: a single-centered, retrospective, observational study. Lancet Respir Med. 2020;8(5):475-481. (PMID: 32105632)

8. Zhang JJ, Dong $X$, Cao $Y Y$, et al. Clinical characteristics of 140 patients infected with SARS-CoV-2 in Wuhan, China. Allergy. 2020;75(7):1730-1741. (PMID: 32077115) 
9. Chen $T, W u D, C h e n ~ H$, et al. Clinical characteristics of 113 deceased patients with coronavirus disease 2019: retrospective study. BMJ. 2020;368:m1091. (PMID: 32217556)

10. Wang L, He W, Yu X, et al. Coronavirus disease 2019 in elderly patients: Characteristics and prognostic factors based on 4-week follow-up. J Infect. 2020;80(6):639-645. (PMID: 32240670)

11. Li K, Wu J, Wu F, et al. The Clinical and Chest CT Features Associated with Severe and Critical COVID-19 Pneumonia. Investigative Radiology. 2020 Jun;55(6):327-331. (PMID: 32118615)

12. Deng $Y$, Liu W, Liu K, et al. Clinical characteristics of fatal and recovered cases of coronavirus disease 2019 in Wuhan, China: a retrospective study. Chin Med J (Engl). 2020;133(11):1261-1267. (PMID: 32209890)

13. Pan $L, M u M$, Yang $P$, et al. Clinical Characteristics of COVID-19 Patients with Digestive Symptoms in Hubei, China: A Descriptive, Cross-Sectional, Multicenter Study. Am J Gastroenterol. 2020;115(5):766773. (PMID: 32287140)

14. Zhang G, Hu C, Luo L, et al. Clinical features and short-term outcomes of 221 patients with COVID-19 in Wuhan, China. J Clin Virol. 2020;127:104364. (PMID: 32311650)

15. Guan WJ, Ni ZY, Hu Y, et al. Clinical characteristics of coronavirus disease 2019 in China. N Engl J Med. 2020;382(18):1708-20. (PMID: 32109013)

16. Chen N, Zhou M, Dong X, et al. Epidemiological and clinical characteristics of 99 cases of 2019 novel coronavirus pneumonia in Wuhan, China: a descriptive study. Lancet. 2020;395(10223):507-513. (PMID: 32007143)

17. Mik Mikami T, Miyashita H, Yamada T, et al. Risk Factors for Mortality in Patients with COVID-19 in
New York City. J Gen Intern Med. 2020;1-10. (PMID: 32607928)

18. Henry BM, Lippi G. Chronic kidney disease is associated with severe coronavirus disease 2019 (COVID-19) infection. Int Urol Nephrol. 2020;52(6):11931194. (PMID: 32222883)

19. Bhatraju PK, Ghassemieh BJ, Nichols M, et al. Covid-19 in Critically III Patients in the Seattle Region Case Series. N Engl J Med. 2020;382(21):2012-2022. (PMID: 32227758)

20. Ladha KS, Zhao K, Quraishi SA, et al. The Deyo-Charlson and Elixhauser-van Walraven Comorbidity Indices as predictors of mortality in critically ill patients. BMJ Open. 2015;5(9):e008990. (PMID: 26351192)

21. Zhao Q, Meng M, Kumar R, et al. The impact of COPD and smoking history on the severity of COVID-19: A systemic review and meta-analysis. J Med Virol. 2020;10.1002/jmv.25889. (PMID: 32293753)

22. Alqahtani JS, Oyelade T, Aldhahir AM, et al. Prevalence, Severity and Mortality associated with COPD and Smoking in patients with COVID-19: A Rapid Systematic Review and Meta-Analysis. PLoS One. 2020;15(5):e0233147. (PMID: 32392262)

23. Pranata R, Huang I, Lim MA, Wahjoepramono EJ, July J. Impact of cerebrovascular and cardiovascular diseases on mortality and severity of COVID-19-systematic review, meta-analysis, and meta-regression. J Stroke Cerebrovasc Dis. 2020;29(8):104949. (PMID: 32410807)

24. Aggarwal G, Lippi G, Michael Henry B. Cerebrovascular disease is associated with an increased disease severity in patients with Coronavirus Disease 2019 (COVID-19): A pooled analysis of published literature. Int J Stroke. 2020;15(4):385-389. (PMID: 32310015) 